\title{
Arterial Blood Gases: A Simplified Bedside Approach
}

\section{Vishram Buche*}

Department of Neonatology, Central India's Child Health and Research Institute, Avinisha Towers, Dhantoli, Nagpur 440010, India

*Corresponding author: Vishram Buche, Director, Department of Neonatology, Central India's Child Health and Research Institute, Avinisha Towers, Dhantoli, Nagpur 440010, India, Tel: +919823017254; E-mail: vbuche@gmail.com

Rec date: Feb 09, 2014; Acc date: Jul 07, 2014; Pub date: Jul 09, 2014

Copyright: (C) 2014 Buche V. This is an open-access article distributed under the terms of the Creative Commons Attribution License, which permits unrestricted use, distribution, and reproduction in any medium, provided the original author and source are credited.

\begin{abstract}
Interpretation of Arterial blood gases is an essence of critical care. It helps for the assessment of clinical oxygenation, ventilation and acid-base status in critically ill patients. The four closely inter-related physiological parameters $\mathrm{p}^{\mathrm{H}}, \mathrm{PCO}_{2}, \mathrm{HCO}_{3}$ and $\mathrm{PO}_{2}$ helps to diagnose, monitor and manage the ICU patients. Its correct interpretation and application necessitates the knowledge of basic applied physiology in relation to these parameters. The present article is an attempt for the simplified approach for the bedside interpretation of ABG.
\end{abstract}

Keywords: Arterial blood gases; $\mathrm{pH} ; \mathrm{PCO}_{2} ; \mathrm{HCO}_{3} ; \mathrm{PaO}_{2}$

\section{Basic Introduction of Arterial Blood Gases}

The term arterial blood gas (“ABG” or simply blood gas, with "arterial" left unstated) refers to a specific set of tests performed on arterial blood sample. It provides four key pieces of information: $\mathrm{pH}$, $\mathrm{PO}_{2}, \mathrm{HCO}_{3}$, and $\mathrm{PCO}_{2}$, and thereby clinical Oxygenation, Alveolar ventilation and acid base status. The name blood gas is really a partial misnomer since $\mathrm{H}^{+}$and $\mathrm{HCO}_{3}$ are not gases. Interpretation Arterial blood gases are an important diagnostic tool for the evaluation of Oxygenation, Ventilation and acid base status. This article is basically designed to teach the basic principles of arterial blood gas analysis. A background in respiratory physiology is recommended, but not required to understand this approach. The article is aimed to teach a practical and systematic approach to understanding of oxygenation and acid-base disturbances encountered in clinical practice. For trainees, a review of the basic terminology and physiology is included.

The term hypoxia is a reduced $\mathrm{O}_{2}$ delivery to tissues.

The term hypoxemia is a reduced $\mathrm{O}_{2}$ content $\left(\mathrm{CaO}_{2}\right)$ in arterial blood. A normal $\mathrm{PaO}_{2}$ is dependent on the atmospheric pressure, temperature, inspired $\mathrm{O}_{2}$ concentration $\left(\mathrm{FiO}_{2}\right)$, and the patient's age. Essentially $\mathrm{PaO}_{2}$ is five times $\mathrm{FiO}_{2}$ when it is less than $50 \%$.

A patient can be hypoxemic for two basic reasons; oxygen may not be delivered to the alveolar air sacs (hypoventilation) or oxygen in the alveoli may not enter into the blood stream. Hyperoxia is not a term which is clinically used, however, we hope that our patients have normoxia, or normal levels of oxygen (generally attached to hemoglobin) with or without oxygen supplementation.

A patient can be hypercarbic (elevated levels of $\mathrm{CO}_{2}$ ) $\mathrm{OR}$ hypocarbic (reduced level of $\mathrm{CO}_{2}$ ) in the blood which is due to an inability to normally exchange gas in the lungs.

The terms acidemia and alkalemia refer to alterations in blood $\mathrm{pH}$, and are the result of underlying disturbance(s) (metabolic and/or respiratory). The suffix "-emia" is pertaining to the blood. The terms acidosis and alkalosis refer to the processes that alter the acid-base status. There can be one or more than one of these processes simultaneously present in a patient.
Diseases that alter the acid-base status of a patient can be divided....

\section{Metabolic}

\section{Respiratory}

Metabolic processes are those that primarily alter the $\mathrm{HCO}_{3}$ concentration in the blood. A decrease in serum $\mathrm{HCO}_{3}$ (an alkali or base) leads to a metabolic acidosis, while an increase in serum $\mathrm{HCO}_{3}$ leads to a metabolic alkalosis [1-3].

\section{Bicarbonates are of two types but which is clinically important?}

Actual Bicarbonate: The plasma $\mathrm{HCO}_{3}$ is a commonly used parameter for Interpretation and is easily calculated from $\mathrm{PaCO}_{2}$ and pH using Henderson-Hasselbalch equation.

Standard Bicarbonate: This is plasma bicarbonate obtained after the blood has been equilibrated at $37^{\circ} \mathrm{C}$ with a $\mathrm{PaCO}_{2}$ of $40 \mathrm{mmHg}$. This is not considered for interpretation $\mathrm{ABG}$. Thus one can afford to forget standard $\mathrm{HCO}_{3}$ in the interpretation context.

Respiratory processes alter the $\mathrm{pH}$ by changing the $\mathrm{CO}_{2}$ levels. Remember $\mathrm{CO}_{2}$ is a respiratory acid. $\mathrm{CO}_{2}$ accumulation causes an acid state in the blood (through carbonic acid), and as respirations (respiratory rate and/or tidal volume) increase, the body eliminates more $\mathrm{CO}_{2}$ (acid) and is left with a respiratory alkalosis. In other words, a decrease in ventilation leads to retention and increased levels of $\mathrm{CO}_{2}$, and thus a respiratory acidosis.

In conclusion, $\mathrm{pH}$ altering processes can be one of four types: Respiratory acidosis, or alkalosis, metabolic acidosis and/or alkalosis. Again, one or more of these processes may be present in a patient with an abnormal acid-base status. One can have two metabolic processes to gather but NOT two respiratory processes simultaneously.

\section{Systematic Analysis of ABG}

Arterial blood gases are obtained for three basic purposes:

1. To determine oxygenation and

2. To determine acid-base status.

3. To determine alveolar ventilation 
Page 2 of 5

To ensure complete interpretation of these points, it is important to systematically examine each component of the arterial blood gas. This article is aimed to elaborate how to systematically determine oxygenation, and then evaluate the acid-base status.

Assessment of Oxygenation i.e. Alveolar: arterial oxygen gradient: (A-a) $\mathrm{DO}_{2}$ ?

\section{(Age and $\mathrm{FiO}_{2}$ dependent derivative)}

An important part of interpreting blood gases is to assess oxygenation. An arterial oxygen concentration of less than $60 \mathrm{~mm} \mathrm{Hg}$, associated with an oxygenation of less than $90 \%$, is poorly tolerated in humans; therefore a $\mathrm{PaO}_{2}$ of less than 60 is termed hypoxemic. However, "normal" oxygenation decreases with age as the lungs become less efficient at diffusing oxygen from the alveolus to the blood. Again, normal oxygenation for age can be estimated

$$
\mathrm{PaO}_{2}=104.2-(0.27 \mathrm{x} \text { age })
$$

Or more crudely, normal oxygenation for age is roughly $1 / 3$ of the patient's age subtracted from 100 . Using this estimation for example a 60 -year-old patient should have a $\mathrm{PaO}_{2}$ of 80 . Values less than this would be considered hypoxemic for age.

Calculating the alveolar: arterial oxygen gradient: (A-a) $\mathrm{DO}_{2}$ can determine if hypoxia is a reflection of hypoventilation (in other words, reduced because of a rise in $\mathrm{PaCO}_{2}, 1 \mathrm{~mm}$ rise of $\mathrm{PaCO}_{2}$ decreases $\mathrm{PaO}_{2}$ by 0.9 in alveolar sac) or due to deficiency in oxygenation. Unlike oxygen (for which alveolar concentrations are higher than arterial concentrations), $\mathrm{CO}_{2}$ is 20 times more freely diffuses across the lung such that the arterial and alveolar concentrations are identical. As patient hypoventilates, $\mathrm{CO}_{2}$ will accumulate in the body (more $\mathrm{CO}_{2}$ is produced through metabolism than can be eliminated) and thus the blood (where we measure it as $\mathrm{PaCO}_{2}$ ).

The carbon dioxide displaces the oxygen in the alveolus. This reciprocal relationship between oxygen and carbon dioxide in the alveolus is described by the alveolar gas equation:

$\mathrm{PAO}_{2}$ (partial pressure of oxygen in the alveolus) $=150-1.25$ $\left(\mathrm{PACO}_{2}\right)$

Where $\mathrm{PAO}_{2}=$ partial pressure of Oxygen in the alveolus.

$\mathrm{PaO}_{2}=$ partial pressure of Oxygen in the arterial blood.

This equation assumes that the patient is breathing room air $(21 \%$ $\mathrm{O} 2$ ) at atmospheric pressure.

\section{Where do 150 come from?:}

(Atmospheric $\mathrm{P}$ - water vapor P) x FIO2. At room temperature, at sea level,

Atmospheric pressure $=760 \mathrm{~mm} \mathrm{Hg}$;

In the lung, the air is fully saturated with $\mathrm{H} 2 \mathrm{O}$, giving a $\mathrm{H} 2 \mathrm{O}$ vapor pressure of about 47 .

Room Air is about $21 \%$, thus at room air, the PAO2 $=0.21(760-47)$ $=149.7$, or about

150.
And

\section{Where does 1.25 come from?}

This is a fudge factor which is derived from the respiratory quotient. The formula actually requires that the $\mathrm{PACO}_{2}$ be divided by the RQ, which is expressed as the ratio of $\mathrm{CO}_{2}$ produced to $\mathrm{O}_{2}$ consumed (and which is related to diet and metabolism). We estimate the RQ to be 0.8 , and 1.25 is the reciprocal of 0.8 .

This value is the partial pressure of $\mathrm{O}_{2}$ within the alveolus. Because the $\mathrm{CO}_{2}$ freely diffuse from arterial blood to alveolar airspaces, the $\mathrm{PACO}_{2}$ is equal to the $\mathrm{PaCO}_{2}$, which is measured in the arterial blood gas [2]. The above equation can then be rewritten as

$$
\mathrm{PAO}_{2}=150-1.25\left(\mathrm{PaCO}_{2}\right)
$$

Thus

$$
\mathrm{A}-\mathrm{a} \mathrm{DO}_{2}=\mathrm{PAO}_{2}-\mathrm{PaO}_{2}
$$

Or

$$
\mathrm{A}-\mathrm{a} \mathrm{DO} 2=\left[150-1.25\left(\mathrm{PaCO}_{2}\right)\right]-\mathrm{PaO} 2
$$

A normal A-a gradient is $10-20 \mathrm{~mm} \mathrm{Hg}$, the gradient increases with advancing age. An increased A-a gradient analyses decreased $\mathrm{O}_{2}$ in the arterial blood compared to the $\mathrm{O}_{2}$ in the alveolus. This infers a process that interferes with oxygen transfer, or in general terms, suggests physiological ventilation-perfusion mismatch. A normal A-a gradient in the face of hypoxemia suggests the hypoxemia is due to hypoventilation and not due to underlying lung disorders. It differentiates ventilatory and oxygenation failure $[4,5]$.

- When the patient is not breathing room air.....

A-a gradient $=\left\{\left(\mathrm{FIO}_{2}\right)(760-47)-(1.25)\left(\mathrm{PaCO}_{2}\right)\right\}-\mathrm{PaO}_{2}$.

\section{Simplified approach to analyze Acid-Base status}

In order to understand the various processes that can co-exist in a patient, one must systematically evaluate the blood gases and serum electrolytes. The article uses 6 simple steps to analyze the acid-base status of the patient.

Normal values and range of ABG parameters

$$
\begin{aligned}
& \mathrm{p}^{\mathrm{H}}: 7.40 \text { (7.35-7.45) } \\
& \mathrm{PCO}_{2}: 40 \text { (35-45) } \\
& \mathrm{HCO}_{3}: 24 \text { (22-26) } \\
& \mathrm{PaO} 2: 100 \text { (90-100) }
\end{aligned}
$$

Just the numerical values doesn't tell you normalcy, all values are to interpreted in the context of each other and with patient's clinical condition (Table 1).

Remember by heart: $\quad\left(\mathrm{CO}_{2}\right.$ is a respiratory acid $)$

$\mathrm{pH}$ and $\mathrm{HCO}_{3}$ : $\quad$ Moves in same direction

$\mathrm{pH}$ and $\mathrm{PCO}_{2}$ : Moves in opposite direction

$\mathrm{HCO}_{3}$ and $\mathrm{PCO}_{2}: \quad$ Moves in same direction (simple disorder)

$\mathrm{HCO}_{3}$ and $\mathrm{PCO}_{2}: \quad$ Moves in opposite directions (Mixed disorder)

Steps in Acid-Base Analysis 
Page 3 of 5

\begin{tabular}{|l|}
\hline Step 1. Consider the clinical settings! Anticipate the disorder! \\
\hline Step 2. Look at the $\mathrm{pH}$ ? \\
\hline Step 3. Who is the culprit for changing pH?...Metabolic / Respiratory process \\
\hline Step 4. If respiratory....... acute and /or chronic And Is metabolic compensation appropriate? \\
\hline Step 5. If metabolic, Is respiratory compensation appropriate? Anion gap increased and/or normal or both? \\
\hline Step 6. Is more than one disorder present? Mixed one?
\end{tabular}

Table 1: Steps in Acid-Base Analysis

\section{Step 1: Consider the clinical settings! Anticipate the disorder!}

Clinical assessment based on clinical settings is an essential first step.

From the history, examination and initial investigations make a clinical decision as to what is the most likely acid-base disorder(s).

This is very important a word of caution there are situations where the history may be inadequate, misleading to the range of possible multiple diagnoses.

Difficult to diagnose are mixed disorders: the history and examination alone are usually insufficient in sorting these out.

1. Vomiting: Metabolic alkalosis

2. Diarrhea: Metabolic acidosis

3. Septicemia: Lactic acidosis

4. Hypotension, Hypoxemia, Shock: Lactic acidosis

5. Diabetes mellitus: Ketoacidosis

6. Pneumonia: Respiratory alkalosis/ acidosis

7. Bronchial asthma: Respiratory alkalosis/acidosis

8. Hepatic failure: Respiratory alkalosis, later on metabolic alkalosis

9. CNS disorders: Respiratory alkalosis

10. Renal disorders: Metabolic acidosis

-Keypoint: Metabolic alkalosis and acidosis can exist together with any respiratory either acidosis or alkalosis. Both respiratory disorders can't occur simultaneously

\section{Step 2: Look at the $\mathrm{pH}$}

The $\mathrm{pH}$ of the arterial blood gas measurement identifies the disorder as alkalemic or acidemic.

$$
\begin{aligned}
& \mathrm{pH}>7.4 \ldots \ldots \ldots \ldots \text { Alkalosis } \\
& \mathrm{pH}<7.4 \ldots \ldots \ldots \ldots \text { Acidosis } \\
& \mathrm{pH}=7.4 \ldots \ldots \ldots \ldots \text {. Normal or mixed disorder }
\end{aligned}
$$

$\mathrm{pH}$ is abnormal in uncompensated, partially compensated but near normal in compensated disorders ( $\mathrm{pH}$ will come to normal range)

\section{STEP 3: Who is responsible for this change in $\mathrm{pH}$ ? Who is the CULPRIT?}

$\mathrm{HCO}_{3} \ldots . .$. METABOLIC $\mathrm{PCO}_{2}$......Respiratory

$>26$..... Met. Alkalosis $>45$..... Respiratory Acidosis

$<22$......Met. Acidosis < 35 ..... Respiratory Alkalosis

It is essential to determine whether the disturbance affects primarily the arterial $\mathrm{PaCO}_{2}$ or the serum $\mathrm{HCO} 3$.

- Respiratory disturbances alter the arterial $\mathrm{PaCO}_{2}$ (normal value 35-45)

- Metabolic disturbances alter the $\mathrm{HCO}_{3}$ (normal value 22-26) $\mathrm{pH}$ returns to normal, not absolutely normal but near normal.

- Initial disturbance and compensation follow "same direction" rule.

If the $\mathrm{pH}$ is low (i.e., the primary and controlling disturbance is acidosis causing acidemia) either the $\mathrm{PaCO}_{2}$ is high or the $\mathrm{HCO}_{3}$ is low (These are the only ways in which the $\mathrm{pH}$ can be low). A high $\mathrm{PaCO}_{2}$ defines a primary respiratory acidosis and a low $\mathrm{HCO} 3$ defines a primary metabolic acidosis.

Conversely, if the $\mathrm{pH}$ is high (i.e., the primary and controlling disturbance is alkalosis causing alkalemia) either the $\mathrm{PaCO}_{2}$ is low or the $\mathrm{HCO}_{3}$ is high (These are the only ways in which the $\mathrm{pH}$ can be high). A low $\mathrm{PaCO}_{2}$ defines a primary respiratory alkalosis and a high $\mathrm{HCO}_{3}$ defines a primary metabolic alkalosis.

\section{Step 4: If respiratory...... acute and /or chronic And Is metabolic compensation appropriate?}

If it is a primary respiratory disturbance,

Is it acute? And/or Chronic

For $10 \mathrm{~mm}$ change in $\mathrm{pCO} 2$

$\mathrm{pH}$ changes as

Acidosis $\left(\uparrow \mathrm{CO}_{2}\right) \mathrm{pH} \downarrow$ acute by 0.08

Chronic by 0.03

Alkalosis $\left(\downarrow \mathrm{CO}_{2}\right) \mathrm{pH} \uparrow$ acute by 0.08

Chronic by 0.03

$\mathrm{HCO}_{3}$ Compensates as

Acidosis $\left(\uparrow \mathrm{CO}_{2}\right) \mathrm{HCO}_{3} \uparrow$ acute by 1 
Chronic by 3

Alkalosis $\left(\downarrow \mathrm{CO}_{2}\right) \mathrm{HCO}_{3} \downarrow$ acute by 2

Chronic by 5

For example,

In an acute respiratory acidosis, if the $\mathrm{PCO}_{2}$ increases from 40 to 50 , you would expect the $\mathrm{pH}$ to decrease from 7.40 to 7.32 .

In an acute respiratory alkalosis, if the $\mathrm{PCO}_{2}$ falls from 40 to 30 , you would expect the $\mathrm{pH}$ to increase from 7.40 to 7.48 .

In chronic respiratory disturbances, there are renal mediated shifts of bicarbonate that alter and partially compensate for the $\mathrm{pH}$ shift for a change in the $\mathrm{PaCO}_{2}$.

In a chronic respiratory acidosis, if the $\mathrm{PCO}_{2}$ increases from 40 to 50, you would expect the $\mathrm{pH}$ to decrease from 7.40 to 7.37.

In a chronic respiratory alkalosis, if the $\mathrm{PCO}_{2}$ decreases from 40 to 30, you would expect the $\mathrm{pH}$ to increase from 7.40 to 7.43 .

Remember: Keep in mind to suspect if

- Compensated $\mathrm{HCO}_{3}$ is > expected: additional metabolic alkalosis is there

- Compensated HCO3 is < expected: additional metabolic acidosis is there

\section{Compensation limits}

1. Compensatory $\mathrm{CO}_{2}$ can go as high as 60 and as low as 10 for metabolic disorders

2. Compensatory $\mathrm{HCO}_{3}$ can go as high as 40 and as low as 10 for respiratory disorders

AND respiratory compensation is faster; takes min to hours to compensate whereas metabolic compensation is slower, may takes days and even week time.

- Respiratory disorders are better compensated than metabolic ones.

- Most predictable compensation occurs in Metabolic acidosis.

- Highly Un-predictable compensation occurs in metabolic alkalosis.

\section{Step 5: If metabolic, Is respiratory compensation appropriate? Anion gap increased and/or normal or both?}

If it is a primary metabolic disorder then is the respiratory compensation adequate or not?

For metabolic acidosis: Expected $\mathrm{PCO}_{2}=\left(1.5 \times\left[\mathrm{HCO}_{3}\right]\right)+8+2$ (Winter's formula) or

Expected $\mathrm{CO}_{2}$ is equal to last two digits of $\mathrm{pH}$ important and easy to remember.

\section{For metabolic alkalosis:}

Expected $\mathrm{PCO}_{2}=6 \mathrm{~mm}$ for $10 \mathrm{mEq}$. rise in $\mathrm{HCO}_{3}$.

Uncertain Compensation

Remember: Keep in mind to suspect if
- Compensated PCO2 is > expected: additional respiratory acidosis is there.

- Compensated PCO2 is < expected: additional respiratory alkalosis is there.

Processes that lead to a metabolic acidosis can be divided into those with an increased anion gap and normal anion gap. The anion gap is the difference between the measured serum cations (positively charged particles) and the measured serum anions (negatively charged particles). (Of course, there is no real gap; in the body the number of positive and negative charges is balanced according to law of electro neutrality. The gap refers to the difference in positive and negative charges among cations and anions which are commonly measured). The commonly measured cation is sodium. (Some people also use potassium to calculate the gap; that results in a different range of normal values, and we will not use potassium to calculate the gap subsequently). The measured anions include chloride and bicarbonate. Thus the anion gap can be summarized as:

$$
\mathrm{AG}=\left[\mathrm{Na}^{+}\right]-\left(\left[\mathrm{HCO}_{3}\right]+\left[\mathrm{Cl}^{-}\right]\right) .
$$

The normal anion gap is 12-18. An increased or even normal anion gap helps for differential diagnosis of a metabolic acidosis. Metabolic acidosis can be normal anion gap (hyperchloremic), and High Anion Gap (normochloremic). Essentially HCO3 loosing disease like e.g. diarrhea, Renal tubular Acidosis causes Hyperchloremic normal anion gap metabolic acidosis, whereas $\mathrm{HCO} 3$ consuming diseases like e.g. Lactic acidosis, Ketoacidosis, renal failure etc. causes Normochloremic High Anion Gap metabolic acidosis. Various mnemonics exist for the causes of an increased anion gap metabolic acidosis; one of which is MULEPAK. The most common etiologies of a metabolic acidosis with an increased anion gap include:

Methanol other alcohols, and ethylene glycol intoxication

Uremia (renal failure)

Lactic acidosis

Ethanol

Paraldehyde and other drugs

Aspirin

Ketones (starvation, alcoholic and diabetic ketoacidosis)

- Keypoint: The true anion gap is underestimated in hypoalbuminemia (=fall in unmeasured anions); $A G$ must be adjusted. Remember to adjust $A G$ :

For every $1 \mathrm{~g} / \mathrm{dl}$ reduction in plasma albumin, anion Gap goes down by 2.5

Beware: A normal anion gap is an increased one in hypoalbuminemia cases though it appears normal numerically.

Simultaneous analysis of Anion Gap and $\mathrm{HCO}_{3}$ : it's easy

It is very helpful in diagnosing mixed disorders. It is determined by Rise and Fall of Anion gap and $\mathrm{HCO}_{3}$ level from its base level

\section{Rationale:}

For each unit Rise in AG: (above normal level), $\mathrm{HCO}_{3}$ should Fall by one unit: (below normal level)

("Normal" values: $\mathrm{AG}=12, \mathrm{HCO}_{3}=24$ ) 
Page 5 of 5

For e.g.:

Is more than one Disorder present?

Proper Clinical history

$\mathrm{pH}$ normal, and $\mathrm{PCO}_{2}$ and $\mathrm{HCO}_{3}$ out of range

$\mathrm{HCO}_{3}$ and $\mathrm{PCO}_{2}$ moving in opposite directions

Degree of compensation for primary disorder is inappropriate.

Look at Rise of anion gap and Fall of $\mathrm{HCO}_{3}$.

How do I assess the correctness or laboratory error.

With help of $\mathrm{H}-\mathrm{H}$ formula it is easy to diagnose,

For example: A report in which $\mathrm{pH}=7.30, \mathrm{HCO}_{3}=30, \mathrm{CO}_{2}=38.1$ though its acidosis neither metabolic nor respiratory since their changed culprit values do not correlate. But

By Henderson-Hasselbach equation:

$\mathrm{H}^{+}=24 \times \mathrm{pCO}_{2} / \mathrm{HCO}_{3}$

$=24 \times(38 / 30)=30$

80 - Last two digit $\mathrm{pH}=\mathrm{H}^{+}$

$80-\mathrm{H}^{+}=$last two digit $\mathrm{pH}$ (after 7)

$\mathrm{pH}$ should have been 7.50

\section{Ten Commandments of ABG:}

1. I shall use only minimal amount of heparin to rinse the syringe. (Heparin changes $\mathrm{pH}$ and if excess dilutional effect)

2. I shall always do ALLEN'S test for collateral circulation and, also ensure that the sample sent is arterial and not venous one.

3. I shall ensure there are no air bubbles in the blood.
4. I shall send the sample in ice and analyze it immediately, and keep the total leucocyte count in mind, esp. when there is a delay.

5. I shall always take $\mathrm{FiO}_{2}$ into consideration when interpreting $\mathrm{PO}_{2}$ values. I shall also look at the $\mathrm{PCO}_{2}$ values with care.

6. I shall take the history into consideration before instituting therapy for chronic respiratory failure.

7. I shall always remember the acronym "DOPE" in situations of sudden deterioration of $A B G$ values

D- Displacement

O- Obstruction

P- Pneumothorax

E- Equipment failure

8. I shall practice gentle mechanical ventilation and not try to bring ABG to perfect normal.

9. I shall treat the patient not the $A B G$ report

10. I shall always correlate ABG report clinically.

\section{References}

1. Martin L (1999) All You Really Need to Know to Interpret Arterial Blood Gases (2ndedn). Lippincott Williams \& Wilkins, USA.

2. Malley WJ (2005) Clinical blood gases (2ndedn) Elsevier Health Sciences, USA.

3. Shapiro BA, Peruzzi WT, Kozelowski-Templin R (1994) clinical application of blood gases.

4. Hennessey I, Japp A (2007) Arterial blood gases made easy, Elsevier Health Sciences, USA.

5. Ashfaq Hasan: Hand book of blood gas/ acid base interpretation. 